\title{
Drug Risk Code
}

National Cancer Institute

\section{Source}

National Cancer Institute. Drug Risk Code. NCI Thesaurus. Code C95363.

A coded value specifying the risk associated with the drug. 